\title{
Experimental and numeric investigation of Impella pumps as cavopulmonary assistance for a failing Fontan
}

\author{
Christopher M. Haggerty, BS, ${ }^{a}$ Francis Fynn-Thompson, MD, ${ }^{b}$ Doff B. McElhinney, MD, ${ }^{c}$ \\ Anne Marie Valente, MD, ${ }^{\mathrm{c}}$ Neelakantan Saikrishnan, PhD, ${ }^{\mathrm{a}}$ Pedro J. del Nido, MD, ${ }^{\mathrm{b}}$ and \\ Ajit P. Yoganathan, $\mathrm{PhD}^{\mathrm{a}}$
}

Objective: This study sought to evaluate the performance of microaxial ventricular assist devices for the purposes of supporting failing Fontan physiology by decreasing central venous pressure.

\begin{abstract}
Methods: Three Abiomed Impella pumps (Abiomed, Inc, Danvers, Mass) were evaluated in a mock circulatory system of the Fontan circuit. The local response of pressures and flows to pump function was assessed as a function of pump speed and pulmonary vascular resistance at a high baseline central venous pressure. For one device, subsequent modeling studies were conducted using a lumped parameter model of the single ventricle circuit.

Results: The left ventricular devices (Impella 2.5, 5.0) were shown to be suboptimal as single device solutions for cavopulmonary support. The small area of these devices relative to vessel diameter led to significant flow recirculation without an obstructive separator in place. Furthermore, downstream pressure augmentation adversely affected the pressure in the superior vena cava. The use of 2 devices would be mandatory for successful support. The right-sided device (Impella RP), whose outflow was positioned in the left pulmonary artery, demonstrated decreased flow recirculation and did not impede superior caval venous flow. Although static pressure is still required to drive flow through the opposite lung, numeric modeling demonstrated the potential for modest but significant improvements in lowering the central venous pressure $(2-8 \mathrm{~mm} \mathrm{Hg})$.
\end{abstract}

Conclusions: Left-sided microaxial pumps are not well suited for cavopulmonary support because of severe flow recirculation and the need for multiple devices. The right-ventricular Impella device provides improved performance by directing flow into the pulmonary artery, resulting in modest decreases in central venous pressure. (J Thorac Cardiovasc Surg 2012;144:563-9)

Without the function of a subpulmonary pump, patients with a single functional ventricle are subjected to drastically altered hemodynamics compared with the normal circulation. Staged surgical palliation to achieve a right heart bypass (the Fontan procedure ${ }^{1}$ ) is the most common treatment strategy, resulting in a total cavopulmonary connection (TCPC). The TCPC requires that the pulmonary blood flow is passively driven by intrathoracic, cardiophasic, and static venous forces. ${ }^{2}$ Chronic exposure to these conditions results in gradual attrition and the development of numerous life-threatening sequelae, ${ }^{3}$ including abnormalities related to altered hepatic and gastrointestinal function or perfusion, such as protein-losing enteropathy, liver fibrosis, and cirrhosis. ${ }^{4,5}$

\footnotetext{
From the Wallace H. Coulter Department of Biomedical Engineering, ${ }^{a}$ Georgia Institute of Technology and Emory University, Atlanta, Ga; and Departments of Cardiac Surgery ${ }^{\mathrm{b}}$ and Cardiology, ${ }^{\mathrm{c}}$ Children's Hospital Boston and Harvard Medical School, Boston, Mass.

Disclosures: Authors have nothing to disclose with regard to commercial support.

Received for publication Sept 7, 2011; revisions received Nov 22, 2011; accepted for publication Dec 14, 2011; available ahead of print Feb 16, 2012.

Address for reprints: Ajit P. Yoganathan, PhD, The Wallace H. Coulter Distinguished Faculty Chair in Biomedical Engineering and Regent's Professor, Associate Chair for Research, Wallace H. Coulter Department of Biomedical Engineering, Georgia Institute of Technology and Emory University, 313 Ferst Drive, Atlanta, GA 30332 (E-mail: ajit.yoganathan@bme.gatech.edu).

$0022-5223 / \$ 36.00$

Copyright (c) 2012 by The American Association for Thoracic Surgery doi:10.1016/j.jtcvs.2011.12.063
}

The concept of mechanical compensation for the missing ventricle of the Fontan circulation is a popular hypothesis for improving these hemodynamics. ${ }^{6-12}$ The basic idea of such an approach is to deploy the cavopulmonary assist device inside or parallel to the TCPC to simultaneously reduce the systemic venous pressure head while augmenting pulmonary pressures and flows. Because of the unique hemodynamic requirements of this operating environment compared with those of the left ventricle (for which most existing mechanical blood pumps are designed), most advocates have proposed novel device designs for this application. ${ }^{6,10,12}$ Although such devices have the potential for long-term benefit, the significant time required for development, testing, and regulatory review impairs their ability to fulfill the immediate need for such therapies.

Alternatively, this study investigates the possibilities for using existing ventricular assist devices for cavopulmonary assistance, particularly focusing on a number of different percutaneous axial flow Impella devices developed by Abiomed, Inc (Danvers, Mass). By using a combination of experimental and numeric models of failing Fontan circulation (ie, having high central venous pressures [CVPs]), the specific objective was to characterize the local response of pressures and flows at the level of the TCPC to assess the viability of the specific devices for the cavopulmonary application. 


$$
\begin{aligned}
& \text { Abbreviations and Acronyms } \\
& \text { CVP = central venous pressure } \\
& \text { IVC = inferior vena cava } \\
& \text { LPA = left pulmonary artery } \\
& \text { PA }=\text { pulmonary artery } \\
& \text { PVR = pulmonary vascular resistance } \\
& \text { RPA }=\text { right pulmonary artery } \\
& \text { RPM = revolutions per minute } \\
& \text { SVC = superior vena cava } \\
& \text { TCPC = total cavopulmonary connection }
\end{aligned}
$$

\section{MATERIALS AND METHODS \\ Experimental Setup}

A mock circulatory loop of the cavopulmonary connection was constructed to experimentally evaluate pump performance (Figure 1, A). Separate steady, submersible pumps were used to continuously fill the superior and inferior central venous reservoirs to the desired pressure level. The system was noncompliant in that a fixed circulating fluid volume was not enforced. A rapid-prototyped replica of a patient-specific lateral tunnel TCPC from a 19-year-old Fontan case was used as the experimental model (Figure 1, B). An atrial overflow reservoir was placed downstream of the pulmonary arterial branches to fix the atrial pressure at $12.5 \mathrm{~mm} \mathrm{Hg}$. Adjustable clamps were also placed downstream of the TCPC to set the pulmonary vascular resistance (PVR). Flow rates were measured using Transonic flow probes (Transonic Inc, Ithaca, NY) in the inferior vena cava (IVC), left pulmonary artery (LPA) and right pulmonary artery (RPA). The superior vena cava (SVC) flow rate was estimated as the difference between the branch pulmonary artery (PA) and IVC rates. Pressure ports were placed at uniform distances from the connection to measure static fluid pressure via vertical water column height.

\section{Investigated Devices}

Three Abiomed microaxial pumps were tested: 2 left ventricular assist devices of varying size motors (Impella 5.0 and Impella 2.5) and a right ventricular device (Impella RP) (Figure 1,C). The LV devices were deployed via insertion through the SVC (simulating a cutdown of the jugular vein) and passed into the TCPC such that the inlet was positioned in the IVC and the motor and outlet were immediately inferior to the IVC-PA junction (Figure 1, D). On the basis of concerns of flow recirculation about the body of the device, experiments with the 5.0 were conducted both with and without an occlusive plug in place to separate the inlet and outlet. The RP device, which has the same motor as the 5.0 but reversed to direct flow to the distal end, was alternatively inserted through the IVC (simulating femoral venous access) and directed into the branch LPA (Figure 1,E).

\section{Experimental Conditions}

Experiments were conducted at a CVP of $20 \mathrm{~mm} \mathrm{Hg}$ to approximate chronically elevated Fontan pressures at a level that may warrant clinical consideration for mechanical support. Pulmonary pressures and flows were subsequently varied by imposing alternate PVR levels of $0.5,1.5$, and $3.0 \mathrm{~mm} \mathrm{Hg} \cdot \mathrm{min} / \mathrm{L}$ (taking the difference between proximal pulmonary and atrial pressures as the transpulmonary gradient). Baseline hemodynamics for these various conditions were established before pump deployment, and results reported as " $\Delta$ " thus represent the change from these baseline conditions.

The acute responses (with respect to cavopulmonary pressures and flows) to pump function were then characterized as a function of pump speed and PVR once the devices were inserted. The exact rotational speeds varied by motor size, but corresponded to the P2, P5, and P9 settings in the pump controller. For the 2.5 model, these speeds were 35,000, 43,000, and 51,000 revolutions per minute (RPM), whereas the 5.0 and RP speeds were 17,000, 24,000, and 33,000 RPM.

Finally, the RP model was tested at the additional CVP condition of 25 $\mathrm{mm} \mathrm{Hg}$ and finer PVR spacing $(0.5-3.0 \mathrm{~mm} \mathrm{Hg} \cdot \mathrm{min} / \mathrm{L}$ in increments of 0.5 ). Baseline measurements were again acquired at these conditions and compared with results with the pump deployed.

\section{Lumped Parameter Modeling}

To complement the experimental investigations, which did not account for ventricular or systemic arterial responses to pump function, lumped parameter modeling, using the model described by Pekkan and colleagues, ${ }^{11}$ was also performed. Details on the structure and formulation for this specific model have been described by Sundareswaran and colleagues. ${ }^{13}$ The existing circuit was modified to allow explicit representation of the RP device according to the experimental design (ie, IVC-to-LPA placement), and the model variables governing pump function ( $\mathrm{A}_{\omega}$ and $\mathrm{R}_{\text {pump }}$; pump inertial constant and internal resistance, respectively) were selected on the basis of the experimental data. All model parameters are provided in Table 1.

\section{RESULTS \\ Left Ventricular Devices}

The experimental results from the Impella 2.5 device (with no occlusive plug in place) as a function of pump speed and PVR are shown in Table 2. A built-in sensor was used to measure flow through the pump at each condition $\left(\mathrm{Q}_{\text {pump }}\right)$, which reached a maximum of $2.3 \mathrm{~L} / \mathrm{min}$ (compared with the designed maximum of 2.5) at the highest RPM setting, and showed little sensitivity to changes in PVR. The changes in IVC flow from baseline, as well as the changes in total pulmonary flow, were less than the reported pump flow in each case, denoting significant recirculation about the device. Further, the recirculation increased with increasing PVR; the total pulmonary flow was less at the $3.0 \mathrm{~mm} \mathrm{Hg} \cdot \mathrm{min} / \mathrm{L}$ condition than at $1.5 \mathrm{~mm}$ $\mathrm{Hg} \cdot \mathrm{min} / \mathrm{L}$. Pressure in the IVC reduced by as much as $2.3 \mathrm{~mm} \mathrm{Hg}$ in the short duration of the experiment; however, SVC pressures increased to levels at or above the PAs in each case.

Table 2 also compares the results of the Impella 5.0 with and without an occlusive plug at $1.5 \mathrm{~mm} \mathrm{Hg} \cdot \mathrm{min} / \mathrm{L} \mathrm{PVR}$. It is noted that no sensor was available on the 5.0 device to measure pump flow. Without the plug, the results mirrored those of the 2.5 device: minimal improvements in pulmonary forward flow and modest decreases in IVC pressure with increases in downstream (SVC and PA) pressures. An asymmetric response with respect to the PA pressures and flows was seen in this case (ie, RPA pressure and flow decreased), which was most likely related to the exact placement and orientation of the pump outlet inside the large lateral tunnel connection.

Once the plug was inserted (removing the potential for flow recirculation around the device), the increase in downstream pressures was accentuated and occurred rapidly with the onset of pump function. Subsequent increases in 


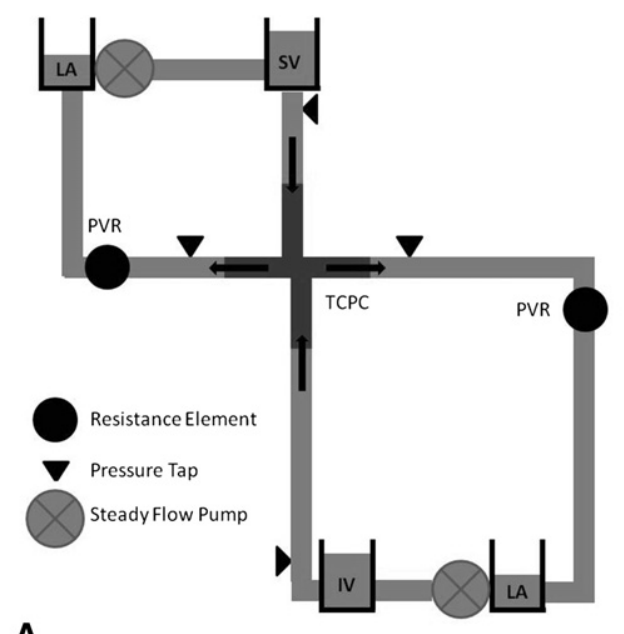

A

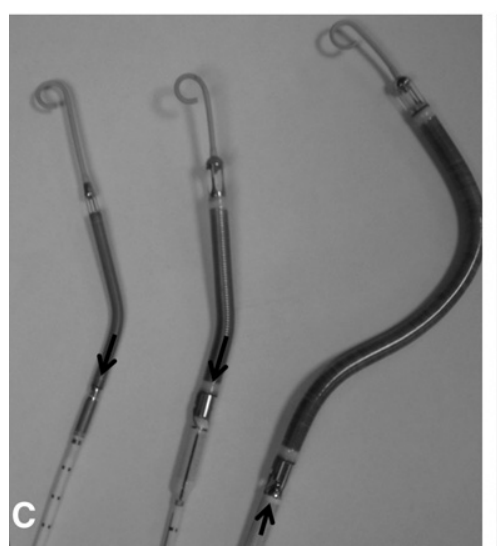

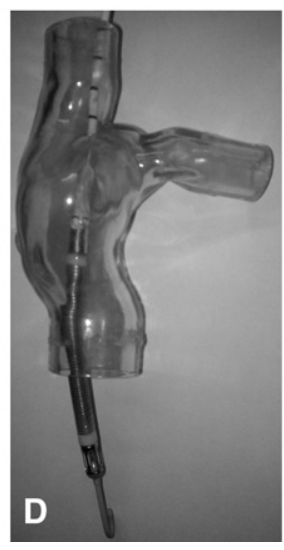

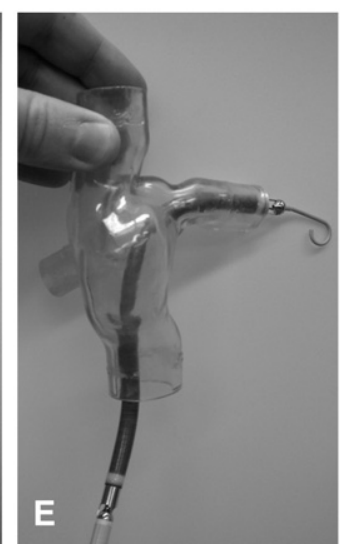

FIGURE 1. Details of experimental setup. A, Schematic of mock circulatory loop. B, Anterior and superior views of computer-aided design model for patient-specific TCPC used in experimental setup. C, The 3 microaxial devices used in the study are 2.5, 5.0, and RP (left to right). Arrows denote position of the motor and direction of flow. D, Positioning of deployed 5.0 device with respect to TCPC model. E, Positioning of the RP device with respect to TCPC model. $L A$, Left atrium; $S V$, superior vein; $I V$, inferior vein; $P V R$, pulmonary vascular resistance; $T C P C$, total cavopulmonary connection; $R P A$, right pulmonary artery; $S V C$, superior vena cava; $L P A$, left pulmonary artery; $I V C$, inferior vena cava.

pulmonary flow ranged from 1.7 to $3.1 \mathrm{~L} / \mathrm{min}$ even though the SVC contribution to pulmonary flow decreased with increasing pump speed.

\section{Impella RP}

As seen in Figure 2, $A$ and $B$, placement of the RP pump in the branch LPA augmented LPA pressure, particularly with increasing pump speed and PVR. The pressure increase was particularly pronounced at the higher baseline CVP, reaching a maximum of approximately $60 \mathrm{~mm} \mathrm{Hg}$ at peak RPM and $3 \mathrm{~mm} \mathrm{Hg} \cdot \mathrm{min} / \mathrm{L}$ PVR. The device also increased LPA flow (Figure 2, C) by up to $1.5 \mathrm{~L} / \mathrm{min}$, decreasing with higher downstream resistance. As with the left ventricular devices, flow recirculation was still present (assessed by subtracting the device flow via the onboard sensor from the measured LPA flow) and increased with higher pump speeds and downstream resistances. With respect to the hemodynamics in the rest of the connection (Table 2), there were minimal acute changes in IVC and
SVC pressure, and small increases in flow. Minor decreases in RPA pressure and flow were noted.

\section{Lumped Parameter Modeling}

Figure 3, $A-C$, shows the predicted physiologic response to RP deployment as a function of pump speed at constant resistance and compliance values (ie, with no allowance for physiologic adaptation or response). Cardiac output progressively improved by virtue of increased ventricular preload (ie, improved diastolic filling; Figure 3, A), which led to subsequent increases in caval flow rates (Figure 3,B). RPA flow decreased slightly with increasing pump speed. With respect to TCPC pressure changes (Figure 3,C), the LPA increased significantly $(\sim 16 \mathrm{~mm} \mathrm{Hg})$ with higher rotational speeds, whereas the other vessels all decreased slightly (IVC $2 \mathrm{~mm} \mathrm{Hg}$ ).

Figure 3, $D$, shows the response of TCPC pressures for a series of different LPA resistances at a constant pump speed. Decreased pressures were observed in each case, 
TABLE 1. Summary of values prescribed in the lumped parameter model

\begin{tabular}{|c|c|}
\hline Parameter & Lumped parameter value \\
\hline $\mathrm{C}_{\mathrm{SV}} \mathrm{Max}, \mathrm{mL} / \mathrm{mm} \mathrm{Hg}$ & 330 (total) \\
\hline $\mathrm{C}_{\mathrm{SA}}, \mathrm{mL} / \mathrm{mm} \mathrm{Hg}$ & 0.5 \\
\hline $\mathrm{R}_{\mathrm{SSV}}, \mathrm{mm} \mathrm{Hg} \cdot \mathrm{min} / \mathrm{L}$ & 45 \\
\hline $\mathrm{R}_{\mathrm{ISV}}, \mathrm{mm} \mathrm{Hg}$ & 40 \\
\hline $\mathrm{C}_{\mathrm{PV}}, \mathrm{mL} / \mathrm{mm} \mathrm{Hg}$ & 80 (total) \\
\hline $\mathrm{C}_{\mathrm{PA}}, \mathrm{mL} / \mathrm{mm} \mathrm{Hg}$ & 4.12 \\
\hline $\mathrm{R}_{\mathrm{RPV}}, \mathrm{mm} \mathrm{Hg} \cdot \mathrm{min} / \mathrm{L}$ & 7 \\
\hline $\mathrm{R}_{\mathrm{LPV}}, \mathrm{mm} \mathrm{Hg} \cdot \min / \mathrm{L}$ & 8 \\
\hline $\mathrm{R}_{\mathrm{TCPC}}, \mathrm{mm} \mathrm{Hg} \cdot \mathrm{min} / \mathrm{L}$ & 3.0 \\
\hline $\mathrm{R}_{\mathrm{MV} / \mathrm{AV}}, \mathrm{mm} \mathrm{Hg} \cdot \mathrm{min} / \mathrm{L}$ & 0.01 \\
\hline $\mathrm{C}_{\mathrm{V}}(\mathrm{min}), \mathrm{L} / \mathrm{mm} \mathrm{Hg}$ & 0.03 \\
\hline $\mathrm{C}_{\mathrm{V}}(\max ), \mathrm{mL} / \mathrm{mm} \mathrm{Hg}$ & 12.5 \\
\hline $\mathrm{A}_{\omega}\left(\mathrm{mm} \mathrm{Hg} / \mathrm{RPM}^{2}\right)$ & $1.7 \mathrm{e}-8$ \\
\hline$\underline{\mathrm{R}_{\text {pump }}(\mathrm{mm} \mathrm{Hg} \cdot \min / \mathrm{L})}$ & 0.06 \\
\hline \multicolumn{2}{|c|}{$\begin{array}{l}C \text {, Compliance; } C P C \text {, cavopulmonary connection; } M V \text {, mitral valve; } A V \text {, aortic valve; } \\
P A \text {, pulmonary artery; } P V \text {, pulmonary vein; } R \text {, resistance; } S A \text {, systemic artery; } S S V \text {, } \\
\text { superior systemic vein; } I S V \text {, inferior systemic veins; } V \text {, single ventricle; } A V \text {, aortic } \\
\text { valve; } R P V \text {, right pulmonary vein; } L P V \text {, left pulmonary vein; } A_{\omega}, R_{\text {pump }} \text {, pump } \\
\text { constants. }\end{array}$} \\
\hline
\end{tabular}

most notably an approximate decrease of $3 \mathrm{~mm} \mathrm{Hg}$ in IVC pressure.

Finally, to characterize the response to hypothetic vascular compliance remodeling, the maximum inferior systemic venous compliance was increased $(0.1$ to $0.2 \mathrm{~L} / \mathrm{mm} \mathrm{Hg}$, bringing total compliance from 0.3 to 0.4 ). The LPA resistance was set in the middle range of the previous simulation set $(4 \mathrm{~mm} \mathrm{Hg} \cdot \mathrm{min} / \mathrm{L})$, and the pump speed was kept in the middle range (24k RPM). Figure 3, $E$, shows the subsequent decreases in cardiac output (16\%), RPA flow (26\%), and IVC pressure $(22 \% ; 3.5 \mathrm{~mm} \mathrm{Hg})$.

\section{DISCUSSION}

The concept of using an axial flow pump in the IVC to augment cavopulmonary hemodynamics has been explored. ${ }^{6,7,9,12}$ The potential use and implications of the left ventricular Impella pump designs for this application have been discussed ${ }^{12,14,15}$ but never explicitly examined. The limitations most commonly cited include the need for a recirculation barrier, such as an expandable balloon (which may be a severe hazard in the case of device failure); the substantial operational speeds and pressure generation inherent to a left-sided device; and the potential collapse of upstream vasculature because of high inlet suction. Given the allure of the Impella devices for cavopulmonary application (because of their small size and ability to deploy percutaneously), conclusively testing these hypotheses is a valuable contribution of this work.

The findings of this study largely support the hypothesized outcomes, although it is notable that excessive pressure generation was not observed. The strongest agreement was that without an occlusive barrier, minimal augmentation of forward flow was observed, signaling significant recirculation about the pump. This configuration is both ineffective and potentially harmful to blood elements through continued exposure to high fluid shear stress. However, with the barrier in place, the immediate limitation (more than the potential for pump failure) was the need for a second (SVC-deployed) device ${ }^{8}$ because of the substantial increase in SVC pressures that accompanied IVC augmentation. Given the traditional shape of the TCPC (opposing SVC and IVC orientations), this effect is unavoidable for a single axial device because any augmentation of

TABLE 2. Experimental results

\begin{tabular}{|c|c|c|c|c|c|c|c|c|c|c|}
\hline & RPM & $\mathbf{Q}_{\text {pump }}$ & $\Delta \mathrm{Q}_{\mathrm{IVC}}$ & $\Delta \mathrm{Q}_{\mathrm{SVC}}$ & $\Delta \mathrm{Q}_{\mathrm{LPA}}$ & $\Delta \mathrm{Q}_{\mathrm{RPA}}$ & $\Delta \mathbf{P}_{\text {IVC }}$ & $\Delta \mathbf{P}_{\text {SVC }}$ & $\Delta \mathbf{P}_{\text {LPA }}$ & $\Delta \mathbf{P}_{\mathrm{RPA}}$ \\
\hline \multirow{3}{*}{2.5 pump $(1.5 \mathrm{~mm} \mathrm{Hg} \cdot \mathrm{min} / \mathrm{L})$} & $35 \mathrm{k}$ & 1.5 & 0.3 & -0.1 & 0.1 & 0.1 & -1.1 & 0.5 & 0.5 & 0.3 \\
\hline & $43 \mathrm{k}$ & 1.9 & 0.4 & -0.1 & 0.2 & 0.1 & -1.7 & 0.9 & 0.9 & 0.7 \\
\hline & $51 \mathrm{k}$ & 2.2 & 0.6 & -0.1 & 0.3 & 0.2 & -2.2 & 1.5 & 1.2 & 1.1 \\
\hline \multirow[t]{3}{*}{2.5 pump $(3.0 \mathrm{~mm} \mathrm{Hg} \cdot \min / \mathrm{L})$} & $35 \mathrm{k}$ & 1.5 & 0.1 & -0.1 & 0.0 & 0.0 & -1.1 & 0.4 & 0.5 & 0.5 \\
\hline & $43 \mathrm{k}$ & 1.9 & 0.1 & 0.0 & 0.1 & 0.1 & -1.3 & 1.2 & 1.3 & 1.1 \\
\hline & $51 \mathrm{k}$ & 2.3 & 0.2 & -0.1 & 0.1 & 0.1 & -2.0 & 1.9 & 1.8 & 1.6 \\
\hline \multirow[t]{4}{*}{5.0 pump* No plug } & $17 \mathrm{k}$ & & 0.5 & -0.5 & 0.2 & -0.1 & -0.7 & 0.5 & 0.9 & -0.5 \\
\hline & $24 \mathrm{k}$ & & 0.3 & -0.1 & 0.3 & -0.1 & -1.4 & 1.1 & 1.9 & -0.6 \\
\hline & $33 \mathrm{k}$ & & 0.3 & 0.1 & 0.6 & -0.2 & -2.6 & 2.1 & 3.9 & -0.6 \\
\hline & & & $\mathrm{Q}_{\mathrm{IVC}}$ & & & & & & & \\
\hline \multirow[t]{3}{*}{5.0 pump* With plug } & $17 \mathrm{k}$ & & 1.8 & -0.1 & 1.2 & 0.5 & N/A & 4.1 & 3.4 & 3.5 \\
\hline & $24 \mathrm{k}$ & & 2.7 & -0.5 & 1.5 & 1.0 & N/A & 8.0 & 6.4 & 5.6 \\
\hline & $33 \mathrm{k}$ & & 3.7 & -1.0 & 1.7 & 1.4 & N/A & 11.5 & 8.8 & 7.8 \\
\hline \multirow[t]{3}{*}{ RP pump* $20 \mathrm{~mm} \mathrm{Hg} \mathrm{CVP}$} & $17 \mathrm{k}$ & 1 & 0.2 & 0.0 & 0.2 & -0.1 & 0.0 & 0.0 & 3.4 & 0.0 \\
\hline & $24 \mathrm{k}$ & 2.5 & 0.3 & 0.2 & 0.6 & -0.1 & 0.0 & 0.0 & 8.2 & 0.0 \\
\hline & $33 \mathrm{k}$ & 4.1 & 0.6 & 0.5 & 1.2 & -0.1 & -0.3 & -0.3 & 10.8 & -0.5 \\
\hline \multirow[t]{3}{*}{ RP pump* $25 \mathrm{~mm} \mathrm{Hg} \mathrm{CVP}$} & $17 \mathrm{k}$ & 1.2 & 0.2 & 0.0 & 0.3 & 0.0 & 0.0 & 0.0 & 4.8 & -0.1 \\
\hline & $24 \mathrm{k}$ & 2.6 & 0.3 & 0.0 & 0.6 & -0.2 & 0.0 & 0.0 & 12.0 & -0.1 \\
\hline & $33 \mathrm{k}$ & 4.1 & 0.5 & 0.3 & 1.1 & 0.0 & -0.1 & 0.0 & 16.3 & -0.2 \\
\hline
\end{tabular}

$N / A$, Not applicable; $Q_{\text {pump }}$, flow value reported by pump sensor; $\Delta$, difference from baseline value. $* \mathrm{PVR}=1.5$. 

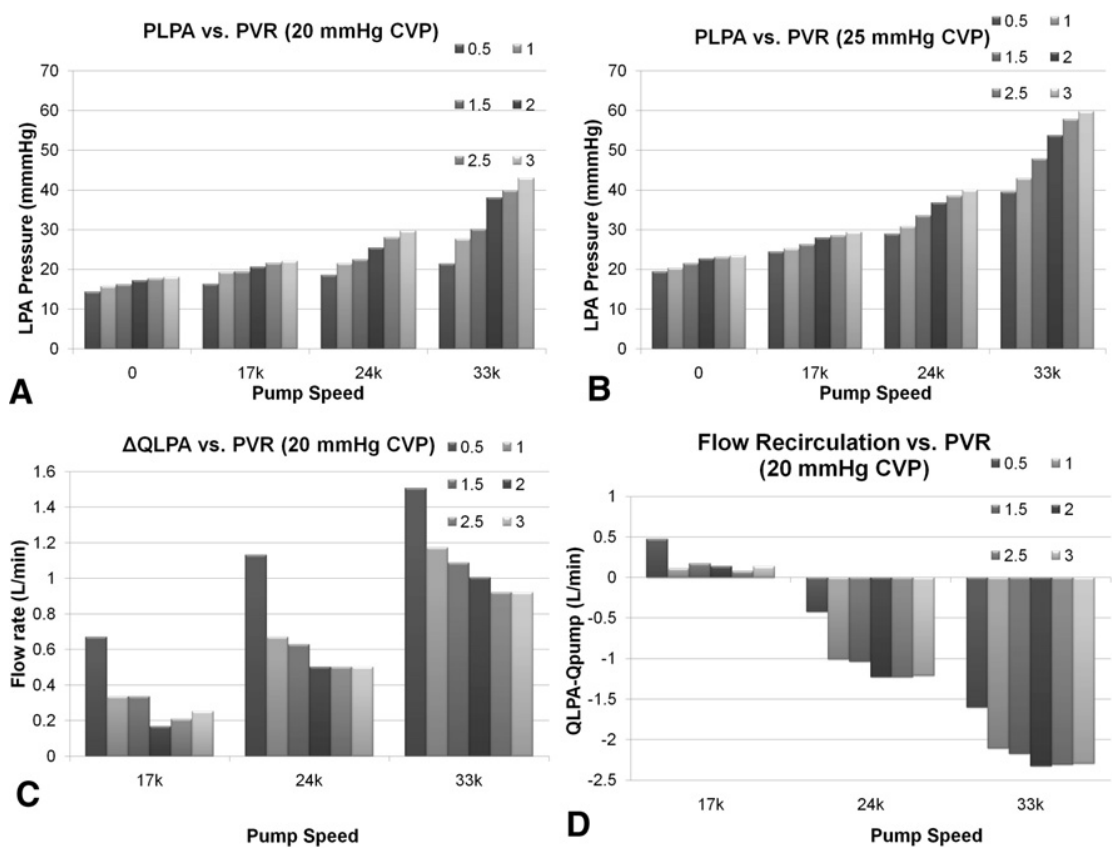

FIGURE 2. Detailed experimental results for the RP device showing the responses of (A, B) LPA pressure (at different baseline CVP values), LPA flow (C), and flow recirculation (D) as functions of pump speed (horizontal axes) and PVR (column colors). LPA, Left pulmonary artery; $C V P$, central venous pressure; $P V R$, pulmonary vascular resistance; $P L P A$, left pulmonary artery pressure; $Q L P A$, left pulmonary artery flow.

pulmonary arterial pressure will occur equally or greater in the SVC.

The implications of SVC hypertension in this setting are debatable. On the one hand, the use of "one-and-a-half ventricle" repair to palliate certain complex congenital heart defects suggests that the SVC pressure can safely be elevated to near normal levels of pulmonary arterial pressure. $^{16,17}$ However, there is phasic variability to those pressure waves - a short duration of elevated systemic pressure, followed by a significant duration of lower mean pressure. That is a critical distinction from the constant high pressure state that would be imposed by axial flow support, because venous compliance could no longer act as a shield against phasic variability to protect the upstream organs. Furthermore, patients targeted for cavopulmonary assist interventions may have a combination of factors resulting in Fontan failure, including issues with venous capacitance and compliance, vascular permeability, and pleural effusions, which could be compounded in an SVC hypertensive state. ${ }^{18,19}$ This physiology may also result in hypertension in the subclavian veins and the thoracic duct, which could therefore lead to problems with fluid homeostasis and the clearance of pleural fluids. ${ }^{20}$ For these reasons, we concur with the assertions of Rodefeld and colleagues ${ }^{8}$ that simultaneous support of both the IVC and SVC is important for axial device approaches. However, the invasiveness of inserting multiple devices may be prohibitive, particularly for smaller patients, and the obstructive flow barrier concerns remain.

\section{Impella RP}

The evaluation of a new right-sided Impella device in the cavopulmonary setting is novel. The experimental results demonstrated that augmentation of pressure and flow to the deployed lung were achieved, with no observed adverse effects on superior caval hemodynamics. The accompanying lumped parameter modeling showed that reductions in CVP were possible. The absolute magnitudes of these decreases will be dependent on the specific response of the patient-specific physiology to pump function; however, these results suggest possible CVP changes on par with levels previously suggested to have a beneficial effect for reversing the Fontan paradox. ${ }^{11}$

Recognizing the inherent dependence of the quantitative findings of the lumped parameter modeling on the assumptions made, a brief justification is warranted. The expected response to increased LPA flow is a decrease in local vascular resistance (eg, vessel dilation) to maintain homeostatic levels of wall shear stress. ${ }^{21}$ Without knowledge of the exact magnitude of the response, the parametric evaluation of LPA resistance values was warranted. As expected, the local flow increased with decreasing levels of pressure generation. The second assumption made was the compliance remodeling. It is well established that patients undergoing the Fontan have severely decreased systemic venous compliance. ${ }^{18}$ This altered physiology results in elevated venous pressures, which are needed to passively drive pulmonary flow; therefore, some compliance recovery could relieve the hypertension. However, the conditions or 

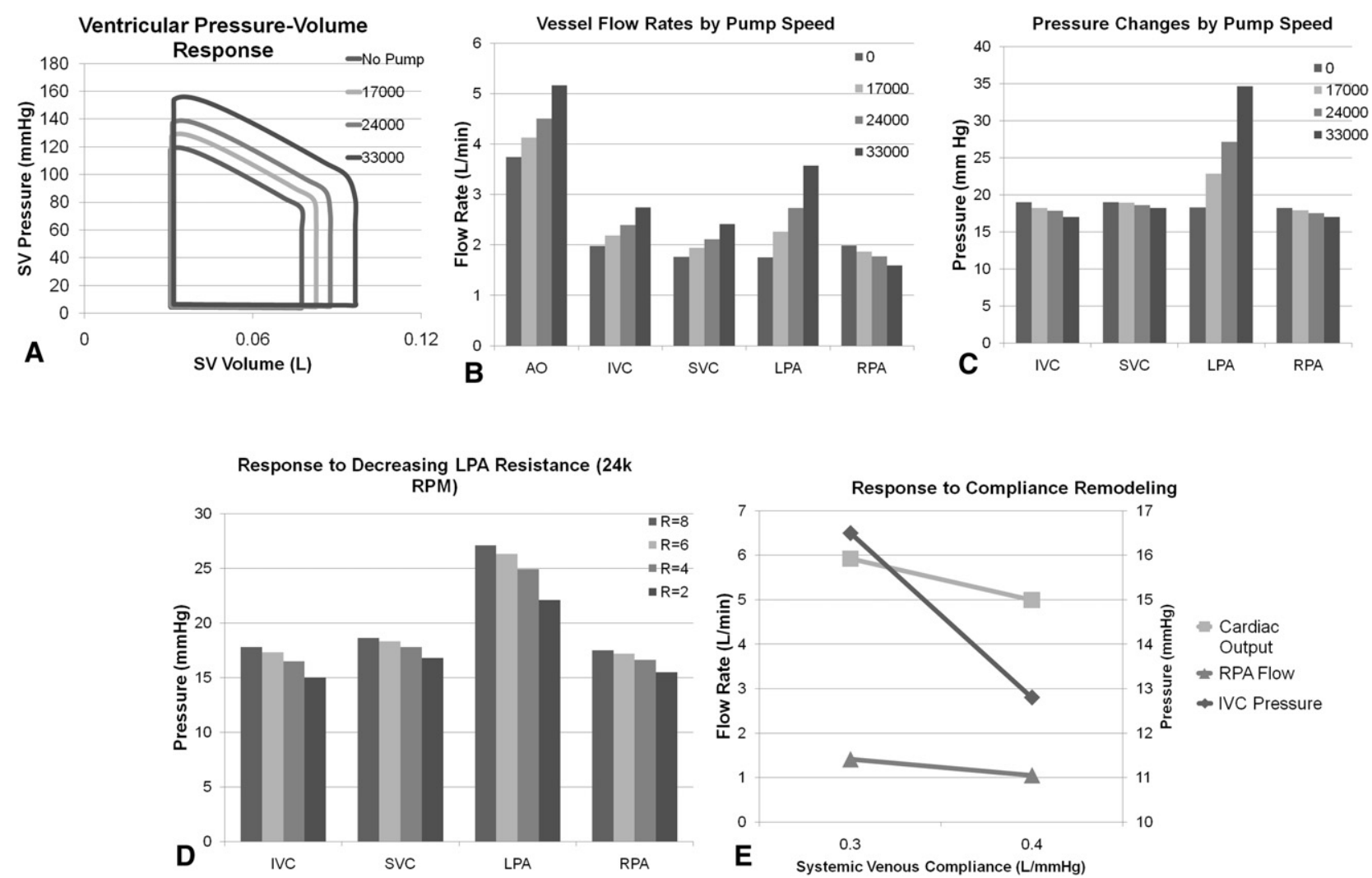

FIGURE 3. Summary of lumped parameter modeling for RP configuration in TCPC. A, Ventricular pressure-volume relationships with increasing pump speed. Changes in vessel (B) flow rates and (C) pressures as a function of pump speed with all other parameters unchanged. D, Pressure response for each TCPC vessel as a function of decreasing LPA resistance ( $\mathrm{R}$, in $\mathrm{mm} \mathrm{Hg} \cdot \mathrm{min} / \mathrm{L})$. E, Changes in cardiac output, RPA flow, and IVC pressure in response to increased systemic venous compliance. $R P A$, Right pulmonary artery; $I V C$, inferior vena cava; $S V$, single ventricle; $S V C$, superior vena cava; $L P A$, left pulmonary artery; $A O$, aorta; $R P M$, revolutions per minute.

mediating factors needed to initiate such a response are not known; any animal modeling done in this space uses acute models that do not undergo such remodeling. The approximation of remodeling was therefore arbitrary, yet conservative compared with "healthy" compliance values (0.4 vs $1.5 \mathrm{~L} / \mathrm{mm} \mathrm{Hg}){ }^{13}$ The response to this small change was significant, suggesting that for patients capable of such vascular adaptation, this intervention could provide a hemodynamic benefit in lieu of therapeutic alternatives.

Despite the demonstrated potential of the RP device as a cavopulmonary assist device in this pilot investigation, several observed limitations of this device are noted in anticipation of further study and testing. The decrease in CVP predicted was limited for the primary reason that a static pressure head was still required to passively drive flow through the contralateral lung. The addition of a pulmonary vasodilator, such as nitric oxide or sildenafil, might improve device effectiveness by lowering PVR and decreasing the venous pressure needed to drive RPA flow. ${ }^{22}$ There is still potential for flow recirculation, although the considerable length of this pump could provide the advantage of extreme distal placement of the pump outlet to further promote forward flow. Finally, the size of the RP may be limiting for minimally invasive deployment, particularly in smaller or younger patients. The predicted success of unilateral lung perfusion could be similarly recreated using other devices, such as external centrifugal pumps with appropriately sized cannulae, in patients in whom size constraints are a concern.

\section{Limitations}

There are several limitations to this preliminary study that preclude a more conclusive statement regarding the success of these therapeutic options. First, stiff tubing was primarily used for the experimental setup such that vessel collapse (from pump suction), which has been previously noted in left-sided devices in this low-pressure setting, could not be assessed. Second, the mock circulatory setup used was simplified and did not incorporate ventricular or systemic arterial responses, as other similar studies have. It was for this reason that lumped parameter modeling was used for the RP device. Explicit experimental representation of these components would require the same assumptions used by the lumped parameter model. Finally, the 
lumped parameter modeling was idealized and hypothesis driven, as opposed to the parameters being dynamically adaptive. Because the actual response is unknown and potentially patient-specific, we cannot claim that the results are exactly representative of what the response of an individual patient will be. Instead, these data serve 3 purposes: (1) demonstrate the potential hemodynamic benefits of cavopulmonary assistance with an Impella RP, (2) reveal potential roadblocks to a successful intervention with an RP-style configuration, and (3) identify the critical variable factors on which future investigations studies should focus in assessing device effectiveness.

\section{CONCLUSIONS}

Three different microaxial, intravascular ventricular assist devices were experimentally evaluated in the context of supporting a patient with a failing Fontan in the hopes of temporarily reversing the Fontan paradox. The left ventricular Impella devices were shown to have severe shortcomings with respect to flow recirculation (and the need for physical separation between the pump inlet and the outlet) and the need for 2 devices (to avoid venous hypertension in the superior systemic circuit). The new right ventricular Impella RP device was experimentally and numerically shown to circumvent some of these shortcomings by laterally directing flow to one branch PA and theoretically achieving moderate decreases in CVP. Although not an ideal solution because of the need for passive flow to the contralateral lung, this device may have the potential to provide targeted benefit to patients with a failed Fontan without other therapeutic alternatives.

Dr Scott Corbett and Abiomed, Inc, provided the devices for the analysis. This study was supported by the Food and Drug Administration through the Pediatric Device Consortium Program and the specific efforts of the Pediatric Cardiovascular Device Consortium (FD003792; PI, Dr del Nido).

\section{References}

1. Fontan F, Baudet E. Surgical repair of tricuspid atresia. Thorax. 1971;26:240-8.

2. Fogel MA, Weinberg PM, Hoydu A, Hubbard AM, Rychik J, Jacobs M, et al. The nature of flow in the systemic venous pathway measured by magnetic resonance blood tagging in patients having the Fontan operation. J Thorac Cardiovasc Surg. 1997;114:1032-41.
3. Gewillig M. The Fontan circulation. Heart. 2005;91:839-46.

4. Rychik J, Goldberg D, Dodds K. Long-term results and consequences of single ventricle palliation. Prog Pediatr Cardiol. 2010;29:19-23.

5. Khairy P, Fernandes SM, John E, Mayer J, Triedman JK, Walsh EP, Lock JE, et al. Long-term survival, modes of death, and predictors of mortality in patients with Fontan surgery. Circulation. 2008;117:85-92.

6. Rodefeld M, Coats B, Fisher T, Giridharan GA, Chen J, Brown J, et al. Cavopulmonary assist for the univentricular Fontan circulation: von Karman viscous impeller pump. J Thorac Cardiovasc Surg. 2010;140:529-36.

7. Throckmorton AL, Ballman KK, Myers CD, Litwak KN, Frankel SH, Rodefeld MD. Mechanical cavopulmonary assist for the univentricular Fontan circulation using a novel folding propeller blood pump. ASAIO J. 2007;53: 734-41.

8. Rodefeld MD, Boyd JH, Myers CD, LaLone BJ, Bezruczko AJ, Potter AW, et al Cavopulmonary assist: circulatory support for the univentricular Fontan circulation. Ann Thorac Surg. 2003;76:1911-6.

9. Riemer RK, Amir G, Reichenbach SH, Reinhartz O. Mechanical support of total cavopulmonary connection with an axial flow pump. J Thorac Cardiovasc Surg. 2005;130:351-4

10. Lacour-Gayet FG, Lanning CJ, Stoica S, Wang R, Rech B, Goldberg S, et al. An artificial right ventricle for failing Fontan: in vitro and computational study. Ann Thorac Surg. 2009;88:170-6.

11. Pekkan K, Frakes D, Zelicourt DD, Lucas C, Parks WJ, Yoganathan AP. Coupling pediatric ventricle assist devices to the Fontan circulation: simulations with a lumped-parameter model. ASAIO J. 2005;51:618-28.

12. Throckmorton AL, Kapadia JY, Chopski SG, Bhavsar SS, Moskowitz WB Gullquist SD, et al. Numerical, hydraulic, and hemolytic evaluation of an intravascular axial flow blood pump to mechanically support Fontan patients. Ann Biomed Eng. 2011;39:324-36.

13. Sundareswaran KS, Pekkan K, Dasi LP, Whitehead K, Sharma S, Kanter K, et al The total cavopulmonary connection resistance: a significant impact on single ventricle hemodynamics at rest and exercise. Am J Physiol Heart Circ Physiol. 2008;295:H2427-35

14. Bhavsar SS, Kapadia JY, Chopski SG, Throckmorton AL. Intravascular mechanical cavopulmonary assistance for patients with failing Fontan physiology. Artif Organs. 2009;33:977-87.

15. Rodefeld M, Frankel SH, Giridharan GA. Cavopulmonary assist: (em)powering the univentricular Fontan circulation. Semin Thorac Cardiovasc Surg Pediatr Card Surg Annu. 2011;14:45-54.

16. Chowdhury UJ, Airan B, Sharma R, Bhan A, Kothari SS, Saxena A, et al. One and a half ventricle repair with pulsatile bidirectional Glenn: results and guidelines for patient selection. Ann Thorac Surg. 2001;71:1995-2002.

17. Kreutzer C, Mayorquim RC, Kreutzer GO, Conejeros W, Roman MI, Vazquez H et al. Experience with one and a half ventricle repair. J Thorac Cardiovasc Surg. 1999;117:662-8.

18. Kelly J, Mack G, Fahey J. Diminished venous vascular capacitance in patients with univentricular hearts after the Fontan operation. Am J Cardiol. 1995;76:158-63.

19. Buchhorn R, Bartmus D, Buhre W, Bursch J. Pathogenetic mechanisms of venous congestion after the Fontan procedure. Cardiol Young. 2001;11:161-8.

20. Allen S, Drake R, Laine G, Gabel J. Effect of thoracic duct drainage on hydrostatic pulmonary edema and pleural effusion in sheep. J Appl Physiol. 1991; 71:314-6.

21. Kamiya A, Togawa T. Adaptive regulation of wall shear stress to flow change in the canine carotid artery. Am J Physiol. 1980;239:H14-21.

22. Reinhardt Z, Uzun O, Bhole V, Ofoe V, Wilson D, Onuzo O, et al. Sildenafil in the management of the failing Fontan circulation. Cardiol Young. 2010;20:522-5. 